\title{
SOCIEDADE E REFORMA AGRÁRIA NO BRASIL
}

Manuel Correia de Andrade*

\section{INTRODUÇĀO}

É muito difícil fazer-se uma análise sucinta da questão da propriedade da terra no Brasil e da luta travada entre os beneficiários na apropriação da mesma e os excluídos de participação nos frutos da produção. Isto, sem falar que, em geral, são os excluídos aqueles que trabalham a terra e a beneficiam em condições de remuneração as mais cruéis.

As análises que vêm sendo feitas por especialistas do direito, como, entre outros, Raymundo Laranjeiras ${ }^{1}$, Otávio Mello Alvarenga ${ }^{2}$ e Igor Tenónio ${ }^{3}$ ou por técnicos dos vários setores, nos dão uma visão bem definida, dentro de enfoques específicos, enquanto cabe aos estudos sociológicos analisar a totalidade; desta visão, não devem ser excluídos aspectos antropológicos, geográficos, econômicos e políticos, que sempre interferem na problemática. Também não se pode excluir, em qualquer proposição, um toque ideológico, de vez que, hoje, ninguém de boa fé pode admitir que haja isenção política ou neutralidade em qualquer reflexão que se ligue à questão social. Para que se alcance uma objetividade, dentro de uma visão totalizadora, necessário se faz uma reflexão histórica, de vez que o presente é plasmado em um passado que continua presente e se projeta para o futuro; qualquer análise

\footnotetext{
* Pesquisador-Diretor da FUNDAJ. Doutor em Economia.

${ }^{1}$ Propedêutica do Direito Agrário. São Paulo, Ed. LTR, 1975.

${ }^{2}$ Direito Agrário. R. J., Instituto dos Advogados do Brasil, 1974.

${ }^{3}$ Manual de Direito Agrário Brasileiro. São Paulo, Resenha.
} 
não pode ser feita como uma espécie de instantâneo do que está marcado na paisagem e nas relações sociais, porque a origem da paisagem atual e das relações existentes, vem se processando lentamente, através dos tempos, e apresenta as tendências e as indicações das projeções futuras. Assim, a cronologia, com a sucessão do passado, presente e futuro, é apenas formal, estando, dialeticamente, o futuro no passado e o passado sendo preservado no futuro. Daí a necessidade de se analisar a questão agrária no Brasil e a problemática a ser corrigida e modifica$\mathrm{da}$, levando-se em conta a formação social que deu origem à mesma, sabendo-se que todas as soluções não são definitivas, elas visam a atingir metas que, antes de se efetivarem, já necessitam de reformulação.

\section{A COLONIZAÇÃO E A PROPRIEDADE DA TERRA.}

Os portugueses, ao conquistarem o Brasil, se apropriaram do seu espaço geográfico e o fizeram com vistas à expansão do capitalismo mercantil, a fim de obterem espaços produtores de matérias primas para o mercado europeu. O processo de colonização foi, assim, um empreendimento comercial ${ }^{4}$, de vez que, no século XVI, Portugal já ultrapassara a fase considerada agrária de sua economia e, com a dinastia de Aviz, já se tornara uma nação essencialmente mercantil ${ }^{5}$.

Os colonizadores, de início, não se preocuparam com a apropriação da terra como propriedade particular, limitaram-se a fazer a exploração extrativista de produtos florestais, sobretudo do pau Brasil, para atender à demanda européia. Só ao compreenderem que a conquista da terra perigava devido à concorrência francesa, se não realizassem o povoamento, é que eles criaram o sistema das capitanias hereditárias e fundaram vilas e povoações; passaram, então, a desenvolver uma agricultura, com grande utilização de capitais ${ }^{6}$, a se apropriarem das terras

\footnotetext{
${ }^{4}$ PRADO JUNIOR, Caio. Formação do Brasil Contemporâneo. São Paulo, Martins, 1944.

${ }^{5}$ AZEVEDO, J. L. Épocas de Portugal Econômico. Lisboa, Livraria Clássica Editora, 1947.

${ }^{6}$ FURTADO, C. Formą̧ão Econômica do Brasil. São Paulo, Companhia Editora
} 
e a utilizar trabalho escravo.

Para disciplinar a atividade agrícola, transplantaram para o Brasil o sistema das sesmarias, já utilizado na conquista do território metropolitano e nas ilhas do Atlântico. As pessoas ricas e que fossem católicas, recebiam dos donatários grande extensão de terras, onde construíam grandes casas fortificadas, guerreavam os indígenas, derrubavam as matas e faziam plantações, pagando um foro à Ordem de Cristo que era, nominalmente, a proprietária de todas as terras do Brasil ${ }^{7}$. Para trabalhar a terra utilizavam escravos índios, vencidos nas guerras, e importavam escravos negros da África, estabelecendo um intenso comércio entre o Brasil e o continente negro, sobretudo Guiné e Angola, passando o negro a ser essencial ao desenvolvimento econômico da terra conquistada.

O sistema das sesmarias predominou em todo o período colonial, e nele os sesmeiros tinham apenas a posse da terra e não o domínio; mas, com o poder de que desfrutavam, exerciam a exploração total das terras que lhes eram destinadas, dominando tanto os escravos, índios e negros, como os que trabalhavam para eles como meeiros ou empregados. Havia, também, sem situação jurídica regulamentada, em grandes áreas distantes dos centros governamentais, grupos de migrantes que, não dispondo de títulos de posse, se estabeleciam em terras que conquistavam, vivendo à margem da administração colonial. Foi reconhecendo a importância destes grupos, que José Bonifácio, antes da Independência, fez extinguir o sistema de sesmarias, substituindo-o pelo "direito de posse".

Do ponto de vista formal, o "direito de posse" foi uma evolução sobre o sistema das sesmarias; ele abria a exploração da terra a pessoas que a haviam conquistado sem dependerem das relações com as autoridades, mas a forma de reconhecimento dificultaria a execução da lei. Esta intervenção do Patriarca da Independência pode ser apontada

Nacional, 1986, 21: ed.

${ }^{7}$ PORTO, C. Estudos sobre o Sistema Sesmarial. Recife, Imprensa Universitária, 1963. 
como uma primeira tentativa, frustrada, de democratizar o acesso à propriedade e à posse da terra.

O sistema do direito de posse vigoraria até os meados do século $\mathrm{XIX}$, quando foi aprovada a lei de acesso à propriedade pelo sistema de compra e venda. Esta lei resultara de uma reação dos proprietários de terra que tremiam ter dificuldades de reter os trabalhadores em suas propriedades quando fosse abolida a escravidão. Eles compreendiam que a escravidão indígena havia sido extinta legalmente, no século XVIII, e que a escravidão negra, condenada pela Inglaterra, teria pouca duração; ela seria abolida, gradativamente, com a extinção do tráfico de negros da África para o Brasil (1850), com a Lei do Ventre Livre (1871), com a Lei dos Sexagenários (1886) e finalmente, com a Lei Áurea (1888). Por isto, as áreas mais dinâmicas haviam iniciado uma política de atração de imigrantes, sobretudo italianos, para trabalharem nos cafezais, e estes fazendeiros, naturalmente, procùravam forçar os mesmos a permanecerem em suas terras por um período expressivo. Do contrário, muitos imigrantes, logo após a chegada ao país, já com alguma experiência no trato dos cafezais, fariam a marcha para o interior, conquistando áreas às florestas ainda não apropriadas.

\section{A REAÇÃO DOS EXCLUÍDOS}

É falsa a idéia, muito difundida, de que não houve grande reação à escravidão no Brasil, por parte dos excluídos. Na verdade, a história brasileira é uma luta permanente dos excluídos do acesso à terra pela obtenção de direitos ligados à possibilidade de exploração da mesma.

Desde a conquista, os indígenas lutaram denodadamente contra os colonizadores que os expropriavam e tiravam a liberdade. As lutas, iniciadas no litoral, continuaram no interior quando eles foram expulsos das melhores terras, dizimados ou aldeados, a fim de serem chamados para o trabalho quando se fazia necessário. Para os trabalhos de sedentarização e de submissão, os colonizadores contaram com o apoio geral dos religiosos que se encarregavam da catequese; muito embora, mesmo entre estes, houvesse os que tomaram o partido dos nativos, como os capuchinhos franceses chefiados por Frei Martinho de Nantes, 
no São Francisco, e alguns jesuítas que seguiam a orientação do padre Luis de Grã No Sudeste, Sul e Centro do Brasil onde, nos primeiros séculos, não se desenvolveu uma agricultura de exportação, e antes da descoberta do ouro, os bandeirantes e entradistas guerrearam e escravizaram tribos inteiras que transportaram para o Leste. Estes episódios estão ligados à guerra que promoveram contra o Território das Missões, onde os jesuítas tentaram organizar um estado teocrático com grande desenvolvimento de atividades artísticas e culturais ${ }^{8}$. Merece referência a chamada Guerra dos Bárbaros, no Nordeste, quando os fazendeiros convocaram bandeirantes paulistas para virem combater os grupos indígenas do sertão nordestino que invadiam as suas fazendas e dizimavam o gado,

$\mathrm{E}$ os índios vêm sendo, até os nossos dias, combatidos, espoliados, explorados e desapropriados de suas terras na Amazônia e no Centro Oeste, em nome da necessidade de conquista do território nacional e da exploração das riquezas naturais, baseada em projetos governamentais. Casos, como o da cassiterita em Rondônia, no Amazonas e no Pará', em que foram liberadas à exploração mineral terras já demarcadas das nações indígenas, são gritantes.

A luta dos negros também foi épica e se iniciou no século XVI, com a própria escravidão africana. Muitas dessas lutas não conseguiram entrar para a história, bloqueadas que foram pelos historiadores oficiais, sempre subservientes aos interesses das elites, e só hoje é que já se reúne farta documentação a respeito. A mais famosa foi, naturalmente, o Quilombo dos Palmares em que os negros fugidos se estabeleceram no sul de Pernambuco e norte de Alagoas e se organizaram em um sistema político-econômico semelhante às organizações africanas, e mantiveram comércio e luta com o próprio governo colonial ${ }^{10}$. Só com o apoio de bandeirantes paulistas é que se conseguiu destruir este redu-

\footnotetext{
${ }^{8}$ VIANNA, H. História do Brasil. São Paulo, Melhoramentos, 1961.

${ }^{9}$ ANDRADE, M. C. A Cassiterita nas Regiões Norte e Nordeste do Brasil. Rio de Janeiro, Brasília, CNPq/CETEM, 1991.

${ }^{10}$ CARNEIRO, E. O Quilombo dos Palmares. São Paulo, Companhia Editora Nacional, 1958, $2^{\mathrm{a}} \mathrm{ed}$.
} 
to negro. Outros focos de resistência negra foram encontrados em diversos pontos do país, como no Maranhão, já no século XIX, quando o preto Cosme chefiou um grande grupo de revoltados e fez luta paralela à desenvolvida pelos balaios contra as tropas imperiais. No Maranhão e na Bahia, províncias que tinham uma elevada população escrava, foram numerosos os quilombos e até revoltas urbanas, como a dos Malês, em $1835^{11}$, em que negros islamizados ameaçaram a população branca de Salvador.

Estas revoltas negras foram freqüentes em vários pontos do território nacional, durante todo o período imperial, e deram origem a quilombos que muitas vezes chegaram quase até os nossos dias, onde grupos negros vivem segregados da população que os cerca.

Negros em lutas contra os poderosos e tentando manter o controle da terra que cultivavam, se aliaram a indígenas, a brancos pobres $\mathrm{e}$ mestiços, posseiros e pequenos proprietários, e enfrentaram as forças governamentais, como ocorreu com a Cabanagem no Pará, com a Balaiada no Maranhão e Piauí e com a Guerra dos Cabanos em Pernambuco e Alagoas ${ }^{12}$.

\section{A EVOLUÇĀO DO CAPITALISMO E A ORGANIZAÇĀO DOS TRABALHADORES RURAIS}

As formas de exploração da terra e a expansão da produção, imprimiram modificações substanciais nas relações de trabalho, intensificando e empobrecendo cada vez mais, os grupos mais pobres. Assim, na passagem da agricultura de meação e do sistema de moradores para o sistema assalariado, os trabalhadores foram afastados do controle dos meios e instrumentos de produção e passaram a receber apenas o salário em moeda ou em vales. Os pequenos produtores foram sendo, gradativamente, afastados das áreas que passavam a ter melhores condições de acesso ao mercado. $O$ uso e a difusão da máquina fizeram cair

\footnotetext{
${ }^{11}$ FREITAS, D. Insurreiçóes Escravas. Porto Alegre, Movimento, 1976, pp. 69-87. ${ }^{12}$ ANDRADE, M. C. de. A Guerra dos Cabanos. Rio de Janeiro, Edições Conquista, 1965.
} 
a demanda de mão-de-obra e os trabalhadores tiveram que fazer migrações sazonais à procura de trabalho, levando-os a um maior grau de empobrecimento.

Em compensação, as facilidades de comunicações os levaram a se organizar para reivindicar direitos e para reagir contra a espoliação de que estavam sendo vítimas. Com a redemocratização do país, a partir de 1946, trabalhadores passaram a se organizar em associações profissionais, tentando formar sindicatos e ligas. Estas iniciaram as suas atividades com o apoio do Partido Comunista, ainda na década de Quarenta, quando ele viveu um curto período de legalidade. A organização em sindicatos era muito dificil, de vez que eles estavam sob controle do Ministério do Trabalho. Ocorreu, porém, que alguns passaram a reivindicar a aplicação de leis que os favoreciam e que não eram cumpridas, através de dispositivos do Código Civil Brasileiro, de 1916, e da própria consolidação das Leis do Trabalho, de 1943. Iniciava-se uma luta que seria aguerrida e que só seria controlada pelo poder público, repressivo, após o golpe de 1964.

As Ligas Camponesas, iniciadas em Pernambuco sob a orientação do deputado socialista Francisco Julião, eram uma sociedade civil, tendo sido bem aceitas e orientadas, sobretudo por pequenos produtores, proprietários e arrendatários, e logo se expandiram por todo o Brasil. Os sindicatos rurais, estimulados nos governos Getúlio Vargas e João Goulart, passaram a ser reconhecidos pelo Ministério e a ter funcionamento regular no periodo final da década de Cinqüenta; eles tinham maior importância e expressão nas áreas em que os trabalhadores rurais haviam sido proletarizados. Embora os trabalhadores reclamassem reclamassem sempre o direito ao acesso à propriedade da terra, $\mathrm{e}$ nas Ligas Camponesas, a primeira reivindicação era a reforma agrária que desejavam se fizesse "na lei ou na marra", nos sindicatos rurais, as reivindicações eram prioritariamente salariais. Posições ideológicas, interesses locais e regionais, influências e disputas de lideranças, provocaram o surgimento de vários movimentos camponeses que amedrontaram as classes dominantes, ocasionando a realização do golpe de 1964. Temiam as mesmas o estabelecimento, sob a orientação de Goulart, de uma república sindicalista. 
A promulgação do Estatuto do Trabalhador Rural (Lei $n^{\circ} 4.214$, de 2 de março de 1963), inspirado pelo deputado trabalhista Fernando Ferrari, estendeu vários direitos dos trabalhadores urbanos ao campo, provocando forte reação dos proprietários; só em alguns estados, como Pernambuco, governado por Miguel Arraes, tentou-se assegurar a aplicação da lei. Posição que provocaria acusações de comunista e de revolucionário contra o mesmo, levando a sua deposição ${ }^{13}$.

Com a vitória do movimento militar de 1964, várias organizações de trabalhadores foram extintas e seus líderes aprisionados e perseguidos, mas os sindicatos rurais foram mantidos, embora com a substituição dos dirigentes por militantes que merecessem a confiança do novo Governo. Em geral eram ligados à Igreja Católica, que se engajara na organização sindical rural no período populista.

Com o controle dos sindicatos, procurou o Governo desenvolver uma política de apaziguamento do campo, de forma a reconhecer direitos mas mantendo as novas estruturas. Daí uma série de medidas assistencialistas, como a incorporação do trabalhador rural entre os associados do Instituto de Previdência, a desapropriação e loteamento de algumas propriedades onde havia maiores litígios, e o desenvolvimento do PROTERRA, que se apresentava como uma reforma agrária consentida, na qual os proprietários ofereciam as terras a serem desapropriadas, geralmente aquelas de menor valor, e indicavam os parceleiros a serem premiados.

\section{A IMPORTÂNCIA DO ESTATUTO DA TERRA}

O Estatuto da Terra (Lei n. 4.504, de 30 de novembro de 1964), promulgado alguns meses após o golpe de estado conservador, representou um documento jurídico de grande importância e, ao mesmo tempo, uma providência para conter o movimento vindo da base em favor de modificações na estrutura fundiária. Na verdade, este movimento de base não era bem articulado e definido; ele defendia uma reforma agrária mas não estabelecia diretrizes para a mesma, nem como seria

${ }^{13}$ MARTINS, J. S. Os Camponeses e a Politica no Brasil. Petrópolis, Vozes, 1981. 
aplicada nas diversas regiões do país. De um modo geral, defendia a idéia de que as terras apropriadas, os latifúndios por dimensão, deveriam ser divididos e entregues a trabalhadores e que os salários deviam ser melhorados. Os estudiosos, que nem sempre tinham influência política e proximidade com o poder, estudavam os tipos de relações de trabalho existentes e procuravam analisar que modificações deveriam ser feitas; alguns agitadores, animados com o sucesso da revolução cubana, procuraram estabelecer guerrilhas em regiões pouco acessíveis, como a de Trombas e Formoso ${ }^{14}$. Do ponto de vista teórico, também se discutia a possibilidade de dividir as terras, integrando as pequenas propriedades em cooperativas, ou de se organizar propriedades cooperativas em que os associados não teriam a propriedade da terra mas apenas quotas das cooperativas e sistemas de exploração coletivistas.

Havia ainda os que consideravam a necessidade de se encaminhar um processo de apoio aos pequenos produtores e aos assalariados. Assim, aos primeiros, se deveria dar acesso fácil ao crédito agrícola official, à assistência agronômica e à organização da comercialização, livrando-os dos intermediários; aos segundos a garantia de suas organizações sindicais e o apoio a reivindicações por melhores salários, melhores condições de trabalho $\mathrm{e}$ a assistência previdenciária. As várias correntes, formadas por socialistas, comunistas, católicos de esquerda, anarquistas, etc., participavam de uma luta desigual contra os defensores da ordem estabelecida e contra os proprietários rurais, sem desenvolverem uma estratégia de luta que os unisse e fortalecesse.

A falta de uma estratégia, a desorganização, o apoio norteamericano, além de outros fatores, provocaram a queda rápida do Governo populista e a ascensão de um Governo conservador com aberta opção pelo capitalismo e com compromissos com o dito "mundo ocidental", em luta com posições bem definidas na chamada guerra fria. $O$ mundo se achava polarizado e havia o temor, por parte dos capitalistas, de um avanço do socialismo nos territórios por eles dominados.

${ }^{14}$ ABREU, S. B. Trombas. A Guerrilha de Zé Porfirio. Brasília, 1985. 
Com planos bem definidos e dispondo de poder militar e do apoio internacional capitalista, o Governo Federal organizou uma lei bem ampla para transformar, de forma conservadora, a realidade agrária brasileira. E esta lei foi o Estatuto da Terra que, para setores revolucionários mais conservadores, pareceu uma concessão ao movimento socialista, mas que, na realidade, encaminhava uma contra-reforma que reforçaria o poder e a solidez da grande empresa frente a mudanças que eram inevitáveis em escala mundial. Ela permitiria, assim, o enfraquecimento do latifúndio tradicional, para criar e desenvolver o latifúndio capitalista moderno, bem mais rentável e explorador.

Este latifúndio modemo se desenvolveria sobretudo nas áreas em povoamento, que se tomavam acessiveis com a construção de rodovias que, partindo de Brasília e de São Paulo, atingiriam áreas em grande parte ocupadas pelo cerrado e por florestas equatoriais, no atual Estado de Tocantins, no Pará, no Mato Grosso, em Rondônia, no Acre, no Amazonas e chegando hoje ao Estado de Roraima. Ai, ao lado e a alguma distância das rodovias, os projetos agrícolas e agro-pastorais, financiados pelo Governo Federal, possibilitavam o desmatamento em larga escala da floresta amazônica para a formação de plantações da Coffea robusta, do cacau e de pastagens. O impacto ecológico seria negativo, de vez que a cobertura vegetal era devastada sem um aproveitamento racional da madeira. Os solos, desnudos e expostos às intempéries, eram laterizados e sofriam a erosão e o transporte para os vales, e as pastagens se tomavam fracas após alguns anos de exploração. $O$ impacto social era impiedoso, provocando a desaculturação dos grupos e tribos indígenas sobreviventes e a expulsão dos posseiros das terras que eles já haviam cultivado. A guerra feita contra índios e posseiros foi das mais cruéis e o morticínio, com ataques diretos, com tocaias e com tomada de mantimentos, fez desaparecer familias inteiras. A questão fundiária voltava aos lances épicos da época da conquista.

Os projetos governamentais de colonização em larga escala, associados à construção de rodovias, fracassaram, como ocorreu na área da Perimetral Norte e na região de Altamira, que seria servida pela Transamazônica, onde chegou-se a construir até uma usina de açúcar. Não menor foi o insucesso com as grandes plantações de cacau e café 
em Rondônia.

O Estatuto da Terra provocou a criação do IBRA (Instituto Brasileiro de Reforma Agrária), responsável pela reforma agrária, e do $\mathbb{N}$ DA (Instituto Brasileiro de Desenvolvimento Agrário), que seria responsável pela política de colonização. Felizmente o legislador já distinguia expressamente reforma agrária de colonização, ao contrário de cientistas sociais mais conservadores que admitiam ser a reforma agrána um projeto gigantesco de colonização. $\mathrm{Na}$ verdade, uma reforma agrária traz em si um compromisso com mudanças de estrutura, enquanto um projeto de colonização, por maior que seja, não apresenta compromissos deste tipo. Os dois institutos coexistiram até que, em 1969, foram integrados em um único Instituto, o INCRA (Instituto Nacional de Colonização e Reforma Agrária).

No periodo militar houve uma abertura maior para o problema da desapropriação de terras, sobretudo em áreas de tensão, ficando estabelecido que a propriedade privada tinha que ter uma função social, a fim de a sua desapropriação, tendo sido criado um Fundo Nacional de Reforma Agrária para tornar possivel a execução desta política; determithou que fosse feito um zoneamento agrário, para efeito de reforma, e uma classificação dos imóveis rurais, de acordo com o módulo e com o nivel técnico de exploração agrícola; determinou ainda a elaboração de planos nacional e regional de reformas agrária a fim de impedir ou dificultar uma açào feita de forma intempestiva no setor e procurou-se estimular o cooperativismo, através da criação de cooperativas integrais de reforma agrária (CIRA), e uma política nacional de cooperativismo (Decreto Lei n. 59, de 21 de novembro de 1966), estimulando os serviços de extensão rural, usando técnicas importadas dos Estados Unidos.

As lideranças sindicais rurais, a princípio temerosas, aceitaram uma atitude de cooperação e procuraram aprofundar as orientações assistenciais, transferindo para o Instituto Nacional de Previdência Social (INPS) a assistência médica e dentária aos trabalhadores; assistência que até então era dada, de forma aleatória, pelos proprietários. Em seguida, à proporção que o regime militar foi abrandando e encontrando resistência nos vários setores da sociedade, puderam os traba- 
lhadores organizar um maior número de sindicatos a nível municipal, de federações a nivel estadual e de confederação - a CONTAG - a nível nacional.

Os avanços e recuos se procediam em função da maior ou menor abertura militar e também das disputas no meio dos trabalhadores, que apresentavam uma grande convergência - a luta por melhores salários $\mathbf{e}$ pela reforma agrária - e muitas divergências em função de interesses regionais e da grande diferença entre os interesses dos pequenos produtores e dos assalariados; essa diferença, ainda hoje enfraquece e perturba o movimento sindical rural. $\mathrm{O}$ movimento é prejudicado ainda pela facilidade com que as associaçães de grandes e médios proprietários copiam os pequenos proprietários, em favor das reivindicações mais retrógradas, atemorizando-os com a possibilidade de perda de suas terras.

A legislação elaborada no periodo militar, apesar de voltada muito mais para o aumento de produção e de produtividade do que para a problemática social, poderia ter trazido um maior equilíbrio ao meio rural se fossem aplicados com mais fidelidade os dispositivos legais por eles promulgados e se fizesse sentir com maior intensidade. Foram poucas as desapropriações de terras e muito mal administradas as que foram feitas, como ocorreu com a Usina Caxangá cujo projeto foi administrado por pessoas ligadas às usinas de açúcar e cujo interesse maior era que o projeto fracassasse. Na realidade, o NCRA, salvo em curtos períodos, como o atual, funcionou mais para impedir do que para fazer uma reforma agrária. $O$ problema da falta de fidelidade chega a tal ponto que nem mais o cadastramento periódico de propriedades cujo conhecimento é da maior importância, vem sendo publicado com regularidade.

\section{A QUESTÃO AGRÁRIA E A CONSTITUIÇÃO DE 1988.}

Se, no período militar, a questão agrária foi desviada de suas diretrizes básicas e os latifúndios aumentaram de extensão nas áreas tradicionais, beneficiadas

por programas os mais diversos, após a chamada Nova Repúbli- 
ca, a política agrária não sofreu modificações substanciais. Observa-se até que, no periodo em que o país sofreu um rápido e intenso processo de modernização, que Graziano classificou como dolorosa ${ }^{15}$, a expulsão do homem do campo para a cidade acelerou-se e a população urbana, no recenseamento de 1991 , atingiu cerca de $75 \%$, sendo, no Sudeste, da ordem de $90 \%$, típica dos países do Primeiro Mundo. A taxa de urbanização elevou-se a mais de $50 \%$ em todas as regiões geográficas do Brasil.

O fato de haver ocorrido uma queda acelerada do percentual de população rural frente à urbana, levou vários estudiosos a afirmarem que desaparecia a importância da questão agrária e, consequentemente, a necessidade desta reforma. A afirmação é uma falácia, de vez que o êxodo rural acelerou-se devido à falta de uma reforma agrária. A mecanização da agricultura, o uso intensivo de insumos, a pecuarização, etc., foram intensificados porque os proprietários foram estimulados pelos novos falsos modernizadores a intensificar, por métodos nem sempre recomendáveis, as suas atividades empresariais e à expulsarem a população rural para as cidades. Livraram-se de um encargo, mas provocaram o grande problema do crescimento desordenado das cidades e da formação de bairros periféricos habitados por pessoas que não encontram trabalho por não disporem de habilitações profissionais urbanas. As cidades "incharam", como disse Gilberto Freyre, e ficaram cheias de pessoas que não têm profissão definida, e que fazem serviços ocasionais, furtam, se prostituem e vagabundeiam, criando problemas sérios de segurança e de saúde. Epidemias que já haviam sido extintas desde o século passado e nas primeiras décadas do século XX, voltaram a atacar a população. Desse modo, com este êxodo rural, os problemas do campo vieram para as cidades.

Muito grave foi o fato que ocorreu durante a elaboração da Constituinte de 1988, quando grupos de deputados ligados ao meio tural, se mobilizaram para impedir a desapropriação, para fíns de reforma agrária, de propriedades consideradas produtivas (art. 185). Ora é difícil estabelecer quando uma propriedade está nesta situação, de vez

${ }^{15}$ SILVA, J. G. Modernização Dolorosa. Rio de Janeiro, Zahar, 1982. 
que, muitas vezes, o proprietário caracteriza a utilização de suas terras apenas usando uma pequena parte da mesma para colocar alguns animais a pastar. Além disto, o Imposto Territorial Rural é muito pouco expressivo no país, fazendo com que proprietários, para se defenderem da inflação sempre em ascensão, adquiram terras a preços baixos e as conservem como reservas de valor.

Assim, apesar da elevada taxa de urbanização, o Brasil continua a ter na questão agrária um dos seus maiores problemas, o que está a reclamar uma solução urgente; solução que atenue o ritmo do êxodo rural, que diminua as migrações sazonais e que leve ao homem do campo uma qualidade de vida semelhante ao do homem urbano que não se encontra ainda na situação de marginal, de favelado.

\section{QUAIS AS DIRETRIZES PARA SE COMPREENDER E SE PROCURAR UMA SOLUÇÃO PARA A QUESTÃO AGRARIA.}

É necessário que o país modifique a sua legislação, taxando com rigor as propriedades de grande extensão - os latifúndios por extensão, sobretudo - e obrigando os seus proprietários a pagar impostos. Devese também orientar, com base em estudos científicos, as culturas, o destino que deve ser dado a estas propriedades, procurando controlar a produção e a produtividade das mesmas.

Deveria haver uma política agricola voltada para o estímulo à produção de alimentos, sabendo-se que o país é um dos maiores produtores de grãos do mundo mas que nele vivem mais de $30 \%$ de sua população atingida por fome aguda. É aconselhável que se realize uma politica de distribuição de terras, de forma cooperativista e coletivista, fazendo voltar para as áreas assim beneficiadas a extensão rural, o crédito agrícola subsidiado e a organização da comercialização. $\mathrm{Na}$ verdade, a agricultura é subsidiada em quase todos os países no mundo, sobretudo quando ela é feita em função do abastecimento da população.

A pesquisa científica e a experimentação agrícola, em um país onde órgãos, como a EMBRAPA (Empresa Brasileira de Pesquisas Agro-Pecuárias), vêm desenvolvendo um trabalho notável, devem ser 
altamente estimuladas, procurando-se desenvolver técnicas modernas, pouco dispendiosas e adaptadas às nossas condições naturais.

Os estudos técnicos e agronômicos devem estar bem associados às pesquisas de ordem antropológica, geográfica, sociológica e econômica, a fim de que se estabeleça sempre a consciência, entre os técnicos e a população, de que os trabalhos são feitos não em função dos interesses dos mesmos, mas em benefício da população como um todo e do país como responsável pelo bem estar de seus habitantes. 